\title{
Evaluation of Pangasius pond sediment potentials in vegetable production as rooftop Bag Gardening
}

\author{
S. Monira*, M. M. Haque, M. M. Ali and M. Y. Prodhan ${ }^{1}$ \\ Department of Aquaculture, Bangladesh Agricultural University, Mymensingh-2202, ${ }^{1}$ Department of Biochemistry and \\ Molecular Biology, Bangladesh Agricultural University, Mymensingh-2202, Bangladesh, *E-mail: smonykaafroje@yahoo.com
}

\begin{abstract}
An experimental research was carried out to assess the potential of Pangasius pond sediment (PPS) on the performance of yield and yield quality attributes of vegetable crop (BARI's tomato variety) grown in bag gardening system on rooftop under integrated aquaculture-horticulture approach. For this purpose, PPS chemical analysis, recording of plant morphological parameters and biochemical analysis of yield were performed. The plants were grown in $100 \%$ PPS $=\mathrm{T}_{1} ; 50 \%$ PPS $+50 \%$ Virgin soil (VS) $=\mathrm{T}_{2} ;$ and $60 \% \mathrm{VS}+40 \%$ Cowdung $+50 \mathrm{~g} \mathrm{TSP}+50 \mathrm{~g} \mathrm{MoP}$ $=\mathrm{T}_{3}$. To compare with PPS treated treatments, treatment $\mathrm{T}_{3}$ was considered as control because it is a standard and recommended fertilizing dose of BARl's tomato production. The PPS sediments were collected from different aged ponds ranging from 1 to 5 years Pangasius culture. The old PPS was used in bag gardening for the determination of soil physico-chemical, plant morpho-physiological and production parameters. All PPS in bags were belonged to silt loam in texture. The total nitrogen level was higher in $\mathrm{T}_{1}$ where $100 \%$ PPS was used. The $\mathrm{T}_{1}$ had the plant height $77.98 \mathrm{~cm}$, number of leaves per plant 184.33 , leaf area $622.49 \mathrm{~cm}^{2}$, which were significantly $(p<0.05)$ higher than $T_{2}$ and $T_{3}$. In the case of phenological development, onset of early flowering and fruiting was noticed in $T_{1}$, which was almost 1.5 weeks earlier than $\mathrm{T}_{2}$ and 2 weeks than $\mathrm{T}_{3}$. The reproductive characters like flowers per plant (28.67), weight of fruit per plant $(53.78 \mathrm{~g})$ and fruit yield per bag $(1945.74 \mathrm{~g})$ and total biomass of plants after harvesting (119.47g) were also significantly $(p<0.05)$ higher in $T_{1}$ followed by $T_{2}$ and $T_{3}$ (control). The numbers of branches per plant (29.54), number of clusters per plant (35.84) and fruits per cluster (5.10) were higher in $T_{1}$ than $T_{2}$ and $T_{3}$. The vitamin $\mathrm{C}$ content of tomato $(28.26 \mathrm{mg} \%)$ was also significantly $(\mathrm{p}<0.05)$ higher in $\mathrm{T}_{1}$ followed by $\mathrm{T}_{2}(24.67 \mathrm{mg} \%)$ and $\mathrm{T}_{3}(21.28 \mathrm{mg} \%)$. The treatment $\mathrm{T}_{1}$ showed the best performance followed by $\mathrm{T}_{2}$ and $\mathrm{T}_{3}$ (control). The perceived aquaculture waste of PPS had the high potential to grow vegetables with better production without any manure and chemical fertilizers. Therefore, PPS could reduce use of chemical fertilizers, especially urea which is environment friendly and less costly for vegetable production in bag gardening system.
\end{abstract}

Keywords: Pangasius pond sediment, Morpho-physiological parameter, Vitamin C

\section{Introduction}

Bangladesh ranked sixth among the major aquaculture producing countries in the world (DoF, 2011). Aquaculture contributed $39 \%$ of the total fish production in 2008, indicating as the fastest growing food producing sector in Bangladesh (DoF, 2009). The catfish production was estimated to be 117,856 metric tons in 2008-2009; which was 4.36\% of total inland fish production (DoF, 2010). Pangasius is a riverine catfish belonging to the members of the family Pangasidae. Thai Pangasius is one of the most suitable catfishes for rearing in ponds. The estimated total Pangasius production in Bangladesh was about 3,00,000 tones in the year 2008 (Edward et. al., 2010 and Munir, 2009).

Pangasius is one of the best aquaculture species due to its ease of culture, high market demand and well suited to the weather condition and its propagation (Sarker, 2000). It is occupying the third most important freshwater fish within aquaculture sector for its rapid growth and market demand. Pangasius can be fed with kitchen waste, rice bran or pellet feeds at the rate of $2.5 \%$ of their average body weight. About $2 \mathrm{~kg}$ of feed is required to produce $1 \mathrm{~kg}$ of Pangasius fish (Haque, 2009). They utilize $30 \%$ of total nitrogen of supplied feed for their body building and $70 \%$ nitrogen is deposited on the pond bottom (Haque, 2009). This sediment holds a large amount of ammonia which is very harmful for pond water quality and surface environment. The farmers are unable to remove this sediment and subsequent uses due to lack of necessary knowledge, fellow land and available labor in dry season. Decomposed feed materials present in the deposited sediments converted into harmful gases and other substances. Thus Pangasius aquaculture has a vast potential for integrated aquaculture-horticulture using the sediments in the systems for improvement of pond environments and proper growth of fish. 
Pangasius pond sediment (PPS) is a valuable waste as it contains high amount of nitrogen, organic carbon, available sulphur, phosphorus and optimum $\mathrm{pH}$. The use of extra organic and/or inorganic fertilizers can be minimized by applying PPS in the crop field. Bag gardening known as vertical farms or gardens for which bags are filled with soil and plant growing in it. When plant in bags containing growing media are placed on roof termed as rooftop bag gardening (RBG). This bag gardening concept for a small and portable garden is good for the areas where the gardeners may have to continually relocate, as well as for areas where there is little or no healthy soil. Several initiatives aimed at providing and training in the use of these bag gardens have reported high levels of success in terms of improving nutrition, food security, and income.

Different types of vegetables are used for daily consumptions but tomato (Solanum lycopersicum) increases the taste and color in different recipes and food value next to others vegetables. Five-ounce tomato growing in home or green house provides a third of our daily needs for vit- $\mathrm{A}$, vit- $\mathrm{C}$ along with some iron, fiber and B vitamins. In terms of land resources, the alarming population growth, poverty, malnutrition, rapid industrialization and urbanization during the past few decades resulted in remarkable reduction of cultivated land. Therefore, these problems can be minimized partly and quickly by practicing integrated aquaculture- horticulture systems. The adoption of the integrated approach will help the community people economically and environmentally. Therefore, an attempt was taken to establish an integrated aquaculture-horticulture approach by utilizing the PPS effectively to produce tomato (horticultural vegetables) as RBG and to assess the efficiency of sediment nutrients on the growth and production performance of horticultural crop in bag gardening system.

\section{Materials and Methods}

The experiment was carried out on the rooftop of the Dean Office Building, Faculty of Fisheries and in the laboratory of the Department of Aquaculture, Faculty of Fisheries, Bangladesh Agricultural University (BAU), Mymensingh during the period from February, 2011 to April, 2012.

\section{Preparation of soil samples}

PPS samples were collected from Pangasius pond of a farm named Ma Fisheries in Dhanikhola village of Trishal Upazila under Mymensingh district. After filling the bags with dried PPS the bag soil nutrients were analyzed. During sample collection, four sub-samples of PPS were collected from a single pond and ground after dried at room temperature and then mixed together to make a single composite sample.

\section{Physical and chemical analysis of PPS}

The pond soil was analyzed before transplanting the tomato seedling in bag as well as after transplanting. Physical parameters such as soil particle size distribution and textural classes were determined by hydrometer method as outlined by (Bouyoucos, 1927). Among the chemical parameters pH was measured by a glass electrode $\mathrm{pH}$ meter according to Jackson, (1986). The organic matter was obtained by multiplying the content of organic carbon by Van Bemmelen factor of 1.73 (Page, 1982). Total nitrogen content was determined by Semi- Micro-Kjeldahl method. The ammonia was collected in boric acid solution and was titrated with $0.01 \mathrm{~N}$ sulphuric acid (Black, 1965). Available phosphorus was analyzed by $0.5 \mathrm{M} \mathrm{NaHCO}_{3}$ extraction and ascorbic acid reduction method (Matt, 1970). Exchangeable potassium was analyzed by ammonium acetate extraction method. The calcium chloride extraction method was used for the determination of available sulphur.

\section{Design and layout of the experiment}

The Completely Randomized Design (CRD) was used to conduct the experiment comprising three treatments, each containing three replications. The treatments were $\mathrm{T}_{1}=100 \% \mathrm{PPS}, \mathrm{T}_{2}=50 \% \mathrm{PPS}+$ $50 \%$ Vergin soil (VS), and $\mathrm{T}_{3}=60 \% \mathrm{VS}+40 \%$ Cowdung $+50 \mathrm{~g} \mathrm{TSP}+50 \mathrm{~g} \mathrm{MoP}$. Treatment $\mathrm{T}_{3}$ was considered as control because the combination of soil, cowdung and other inorganic fertilizers has been recommended by Bangladesh Agricultural Research Institute's (BARI) tomato culture technology (BARI, 1998). Two tomato seedlings were planted in one bag, which made a single replication. Before this, seeds of tomato (BARI-14) were sown in the nursery bed on 06 February 2011. Twenty five days old tomato seedlings were transplanted for rooftop bag gardening. 


\section{Data collection}

The morpho-physiological parameters were collected at 15 days intervals from planting to harvesting. The data were collected on the vegetative, phenological and reproductive parameters.

Vegetative parameters: Plant height was measured by meter scale, number of branches and leaves per plant were counted accordingly, leaf area and total biomass were recorded.

Phenological parameters: Days to first flowering, fruiting and maturity and days to end of fruit harvest were counted properly.

Reproductive parameters: Number of flower clusters per plant, flowers per cluster, flowers per plant, fruit clusters per plant, fruits per cluster, fruits per plant per week, fruits per plant were counted accordingly, fruit weight per plant and fruit yield were measured properly.

Biochemical parameters: Percent moisture and dry matter content were determined and estimation of vitamin $\mathrm{C}$ was done by dye methods.

\section{Statistical analysis}

One-way analysis of variance (ANOVA) was carried out to test the variation between the treatments. The mean differences were evaluated by DMRT (Duncan's Multiple Range Test) (Gomez and Gomez, 1984). Data were analyzed with the computer based statistical package SPSS.

\section{Results and Discussion}

Table 1. The physico-chemical characteristics of bag soil of the experiment

\begin{tabular}{|l|c|c|c|}
\hline \multirow{2}{*}{ Soil characteristics } & \multicolumn{3}{|c|}{ Treatments } \\
\cline { 2 - 4 } & $\mathbf{T}_{1}$ & $\mathbf{T}_{2}$ & $\mathbf{T}_{3}$ \\
\hline $\mathrm{pH}$ & $6.86 \pm 0.04$ & $6.86 \pm 0.03$ & $7.14 \pm 0.02$ \\
\hline Organic-C (\%) & $3.15 \pm 0.04$ & $1.56 \pm 0.05$ & $4.15 \pm 0.07$ \\
\hline Total-N (\%) & $0.30 \pm 0.00$ & $0.14 \pm 0.00$ & $0.36 \pm 0.01$ \\
\hline Available-P (ppm) & $115.63 \pm 0.68$ & $102.33 \pm 1.03$ & $156.66 \pm 1.03$ \\
\hline Exchangeable-K (ppm) & $106.83 \pm 4.31$ & $65.48 \pm 3.16$ & $402.53 \pm 6.31$ \\
\hline Available-S (ppm) & $86.06 \pm 0.66$ & $51.29 \pm 0.43$ & $31.17 \pm 0.66$ \\
\hline Sand (\%) & $25.71 \pm 0.58$ & $27.71 \pm 0.58$ & $36.37 \pm 0.58$ \\
\hline Silt (\%) & $66.00 \pm 0.00$ & $62.00 \pm 0.00$ & $46.00 \pm 0.00$ \\
\hline Clay (\%) $(8.29 \pm 0.58$ & $10.29 \pm 0.58$ & $17.63 \pm 0.58$ \\
\hline Texture & Silt loamy & Silt loamy & Loamy \\
\hline
\end{tabular}

The soils used in this experiment belonged to the silt loam textural class (Table 1). Soils like silt loam and clay loam have higher agricultural values being less susceptible to become loose and open (Weir, 1989).

\section{Chemical characteristics of PPS}

All soils belonged to slightly acidic to almost neutral in nature. The $\mathrm{pH}(6.86)$ of bag soil in $\mathrm{T}_{1}$ was found in a suitable range of vegetable production which was almost similar to the findings of Monir (2009) who reported the $\mathrm{pH}$ concentration varied from 6.82 to 6.90 in different treatments of the Pangasius farming (Table 1). The percent organic carbon content was varied from 4.15 to 1.56 where the $100 \%$ PPS showed suitable range of OC for vegetable production (Table 1). Hepher (1965) reported that the sediment of carp ponds after 5 year of production had an OC content of $1.99 \%$. This result indicated that the PPS organic carbon was cost effective than the chemical fertilizers used at $T_{3}$. The total nitrogen value $(0.30)$ was stimulating to vegetable production in $100 \%$ PPS containing bag. There was no significant variation between $T_{1}$ and $T_{3}$ bag soil's total nitrogen concentration but had significant difference with $T_{2}$ bag soil. The findings of the present study were higher than that of Karim (2009), who obtained the range of total 
nitrogen from 0.04 to $0.096 \%$. The amount of $P$ was ranged from 156.66 to $102.33 \mathrm{ppm}$ where $T_{1}$ contained $115.63 \mathrm{ppm}$. There was no significant variation occurred in $T_{1}$ and $T_{3}$ but $T_{2}$ had significant variation from others. Bhuiyan (1988) conducted an experiment on different soil series of Bangladesh and found the $P$ content was varied from 2.2 to $140 \mathrm{ppm}$ with a mean value of $21.2 \mathrm{ppm}$. The $P$ requirement in $100 \%$ PPS containing bags was suitable for vegetable production. The $\mathrm{K}$ content was varied from 402.53 to $65.48 \mathrm{ppm}$ among three different bag soils where $T_{1}$ content $106.83 \mathrm{ppm}$. According to Bhuiyan (1988) experiment on different soil series of Bangladesh, the $K$ content was ranged from 39.10 to 132.94 ppm with an average value of $70.38 \mathrm{ppm}$. The $\mathrm{K}$ in $100 \%$ PPS was found at a suitable range for vegetable production. The $S$ content was varied from 86.06 to $31.17 \mathrm{ppm}$ among different bag soils. The maximum $S$ content (86.06ppm) was noticed in $\mathrm{T}_{1}$ and the minimum (31.17 ppm) in $\mathrm{T}_{3}$. The $\mathrm{S}$ content was ranged from 15.29 to $128.05 \mathrm{ppm}$ with a mean of $16.8 \mathrm{ppm}$ which was found in Bhuiyan (1988) experiment on different soil series of Bangladesh.

\section{Vegetative development}

Plant height and branch number: The plant height was measured from 0 to 90 days after transplanting (DAT) and it almost steadily increased with the age of the plant and attained its maximum at 90 DAT. The tallest plant height $(77.98 \mathrm{~cm})$ was observed in $100 \%$ PPS $\left(T_{1}\right)$, whereas, the smallest $(52.79 \mathrm{~cm})$ was observed in $\mathrm{T}_{3}$ (control). The branch number of tomato plant was gradually increased with the growth of the plant at different DAT. The highest branch number (29.54) was recorded in $\mathrm{T}_{1}$ and the lowest (23.33) was in $\mathrm{T}_{3}$. There was a positive relation between plant height and branch number.

Number of leaves and leaf area: The number of leaves was counted from 30 to 75 DAT. The maximum number of leaves (156.71) was recorded in $T_{1}$ and the minimum (96.33) in $T_{3}$ (Fig. 1). Leaf production gradually increased until 60 DAT and then decreased. The number of leaves per plant increased gradually with the advancement of growth stages and decreased thereafter due to leaf abscission and crop aging (Pandey et. al., 1978). Leaf area was increased gradually with the advancement of time until 45 DAT and then declined. The maximum leaf area $(548.00$ square $\mathrm{cm})$ was noticed in $\mathrm{T}_{1}$ and the minimum (383.00 square $\mathrm{cm}$ ) in $\mathrm{T}_{3}$ (Fig. 2). The development of leaf area during optimum vegetative growth was the result of generation of new leaves and expansion of the existing ones. The subsequent reduction in leaf area up to maturity after attaining the maximum was due to very poor development of new leaves, leaf rolling and the age effect resulting from senescence of older leaves (Pandey et. al., 1978).

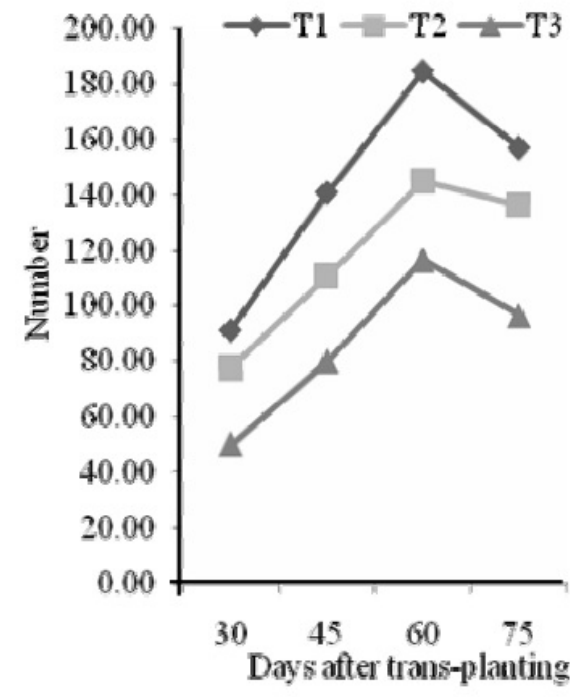

Fig. 1. Number of leaves per treatment in different treatments

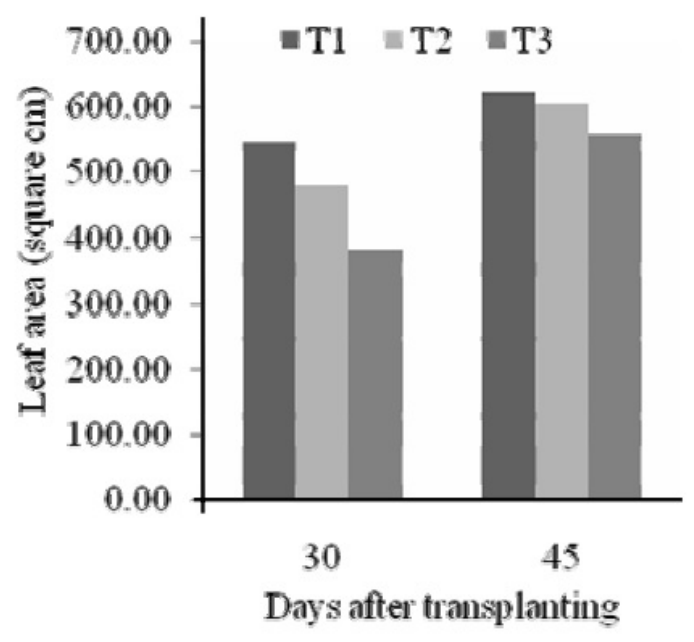

Fig. 2. Measurment of leaf area (square $\mathrm{cm}$ ) in different treatments. 
Phenological development: The early flowering (after 15.67 DAT) was noticed in $\mathrm{T}_{1}$ and late flowering (after 34.67 DAT) was recorded in $\mathrm{T}_{3}$ (control). Early fruiting (after 21.67 DAT) was found in $\mathrm{T}_{1}$ and late flowering (after 39.67 DAT) was recorded in $\mathrm{T}_{3}$ (Fig. 3). Early maturity is one of the important aspects for harvesting of fruit. Total fruit bearing period was also prolonged under $100 \%$ PPS condition. For that reason, total number of harvests was more in $\mathrm{T}_{1}$ than the other treatment.

\section{Reproductive development}

Number of flowers: The number of flowers was measured from 20 to 65 DAT at 15 days of interval. Flower number was significantly influenced the production of crops. It increased gradually with the advancement of time except 65 DAT because, at this stage, all the flowers were converted to fruits. A statistically significant number of flowers were produced by $T_{1}$ from 20 to 50 DAT while $T_{2}$ and $T_{3}$ gave minimum at the same DAT except 50 DAT (Fig. 4).

Number of clusters: The cluster number was measured from 20 to 65 DAT at 15 days interval. It was significantly influenced the production of crops. It increased gradually with the advancement of time for all the treatments. Statistically, $T_{1}$ recorded better cluster from 20 to 35 DAT and 50 to 65 DAT followed by $\mathrm{T}_{2}$ (Fig. 5).

Number of fruits per cluster: It was measured two times at 15 days of interval and increased gradually with the advancement of time for all the treatments at 30 and 45 DAT (Fig. 6). Statistically no significant variation was observed among $T_{1}, T_{2}$ and $T_{3}$ at two different DAT.

Number of fruits per replication: The numbers of fruits were recorded weekly from 30 to 65 DAT and measured as weight/treatment/week. The maximum number (53.78) of fruits was recorded in $T_{1}$ and minimum (22.33) in $T_{3}$. Statistically no significant production was recorded at 30 and 37 DAT in $T_{1}$ and $T_{2}$ but it was increased gradually from 44 to 65 DAT (Fig. 7).

Total production of tomato: Statistically significant $(\mathrm{p}<0.05)$ production was recorded in $\mathrm{T}_{1}(1945.74 \mathrm{~g})$ followed by $\mathrm{T}_{2}$ (1399.74g), whereas, the minimum was recorded in $\mathrm{T}_{3}(888.90 \mathrm{~g})$ (Fig. 8). The total production rate determines the quantity of crops.

\section{Total biomass at different DAT}

Total biomass production: The biomass was recorded two times. At initial stage (seedling stage), total biomass production for all the treatments were almost same but after final harvest it was significantly maximum (119.47g) at $T_{1}$ followed by $T_{2}(93.41 \mathrm{~g})$ (Fig. 9). As the value of other morphological parameters of tomato plant was higher in $\mathrm{T}_{1}$, therefore, total biomass production was also higher.

\section{Biochemical Measurement}

Percent moisture and dry matter content of tomato: The moisture content was ranged from 91.50 to $91.82 \%$ in all the treatments. The maximum amount of moisture content $(91.82 \%)$ was measured in $T_{2}$, whereas, the minimum in $\mathrm{T}_{1}(91.50 \%)$. The dry matter content of tomato was calculated from percent moisture contents. The highest dry matter was found in $\mathrm{T}_{1}(8.50 \%)$ followed by $\mathrm{T}_{3}(8.25 \%)$.

Vitamin C content in tomato fruits: Vitamin C content was varied from 19.28 to $26.26 \mathrm{mg}$ per $100 \mathrm{~g}$ of tomato in all treatments. Treatment $\mathrm{T}_{1}$ contained the highest amount $(26.26 \mathrm{mg})$ of Vitamin $\mathrm{C}$ followed by $\mathrm{T}_{2}$ (22.67mg) whereas $\mathrm{T}_{3}$ had the minimum (19.28mg) (Fig. 10). Statistically significant difference was measured in $\mathrm{T}_{1}$ in compare to other treatments. The above finding was much greater than that of Kalloo (1985) who concluded that tomato contain Vitamin C at the level of $15-20 \mathrm{mg} / 100 \mathrm{~g}$.

Vitamin $\mathbf{C}$ content in tomato fruit: The fresh and pesticide free vegetables are not easily accessible for the urban people as well as rural non-producers. This is because vegetable marketing has a long value chain from rural production area to urban retail market. This long distance transportation of vegetable like tomato potentially reduced the Vitamin C content which is one of the important nutrients for human health. 
Vitamin $\mathrm{C}$ is a great antioxidant and helps protect the body against pollutants. According to WHO, the daily Recommended Dietary Allowance (RDA) of Vitamin C is 45 milligrams per day per person. Therefore, to get required amount of Vitamin $\mathrm{C}$, people need to consume fruits and vegetables as fresh as possible which is possible by bag gardening. After harvesting, Vitamin $\mathrm{C}$ of vegetables is being oxidized from its original reduced form with the passing of time. As a result, Vitamin $C$ content of vegetables is decreased upon transportation and storage. Therefore, growing vegetables (e. g, tomato), spices (e. g, chili) and citrus fruits (lemon and orange etc.) in bag gardening specially in urban areas can get more amount of Vitamin $C$ to inhabitants. In addition, they can get fresh vegetables for their daily need which is good quality, and safe (free from pesticides and chemicals) for human health. The nature of bag gardening in terms of tomato production on the rooftop and its higher level of Vitamin content explains the potential of integrated aquaculture-horticulture using unutilized Pangasius pond sediments.

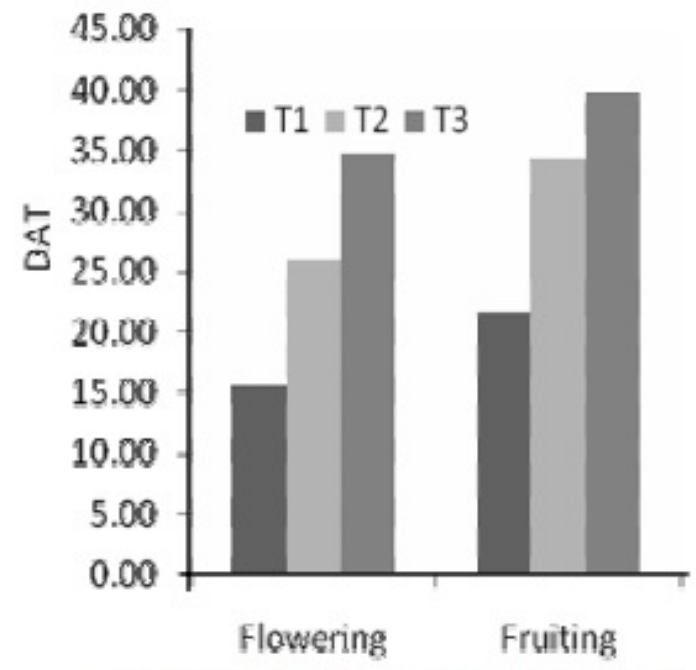

Fig. 3. Onset of flowering and fruiting in tomato plant

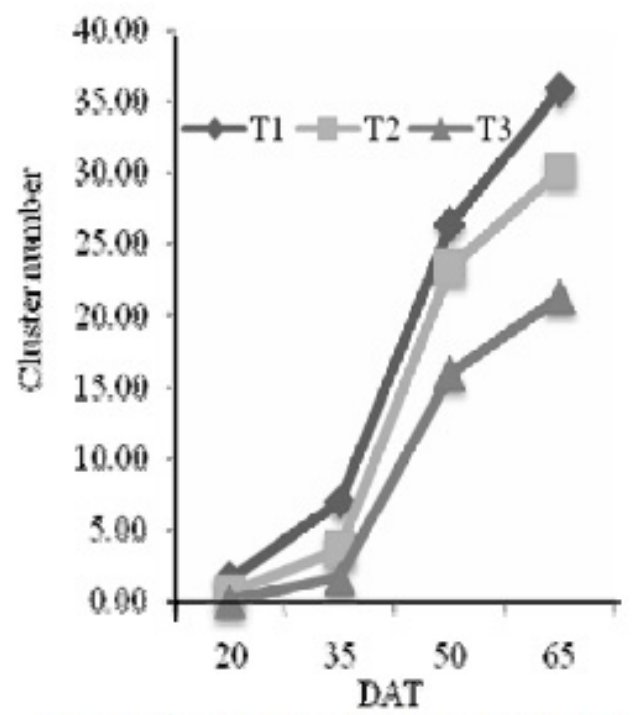

Fig. 5. Number of cluster in different treatments

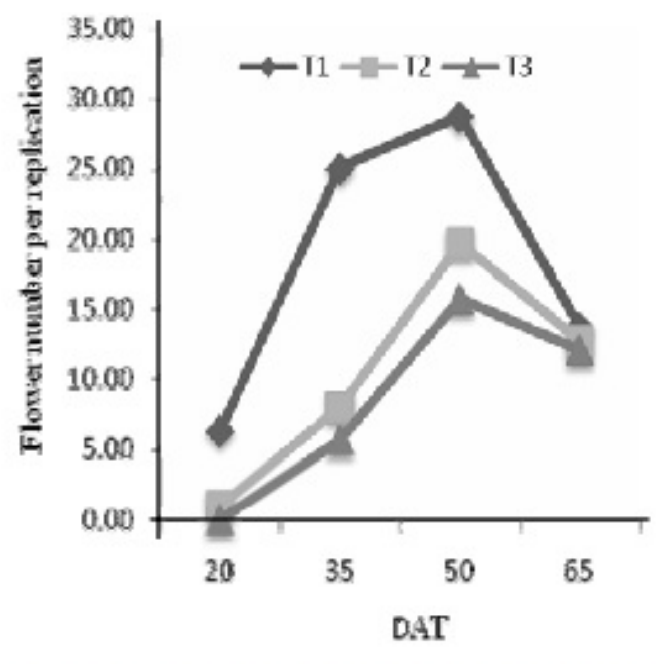

Fig. 4. Flowering pattern in tomato plant in different treatments

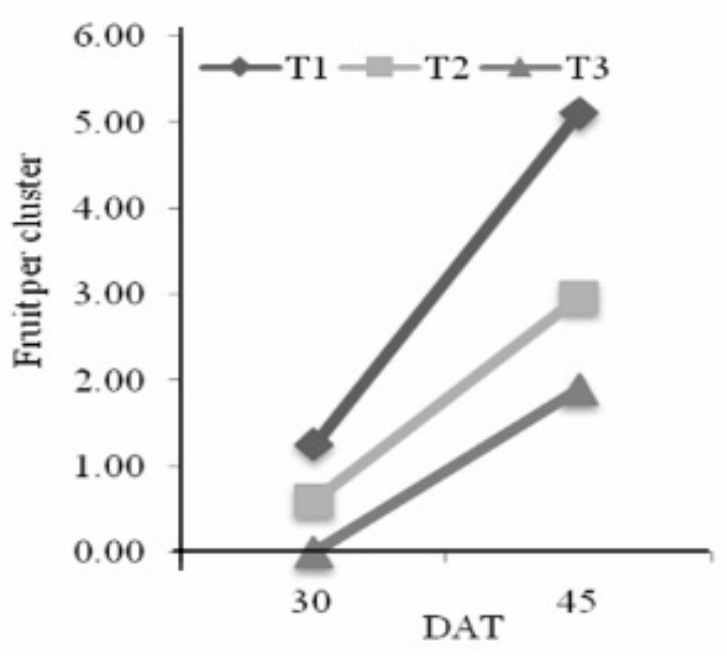

Fig. 6. Number of fruits per cluster in different treatments 


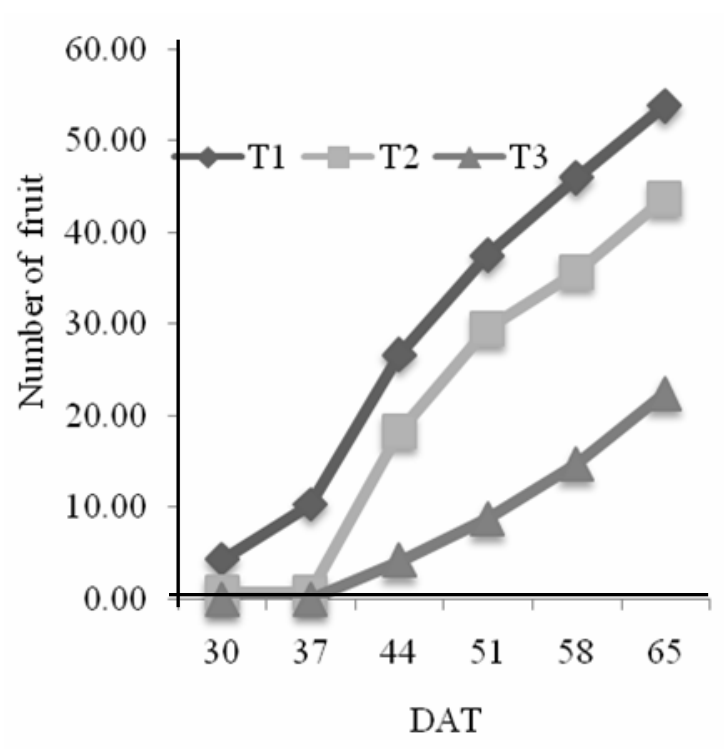

Fig. 7. Number of fruits of tomato plant in different treatments

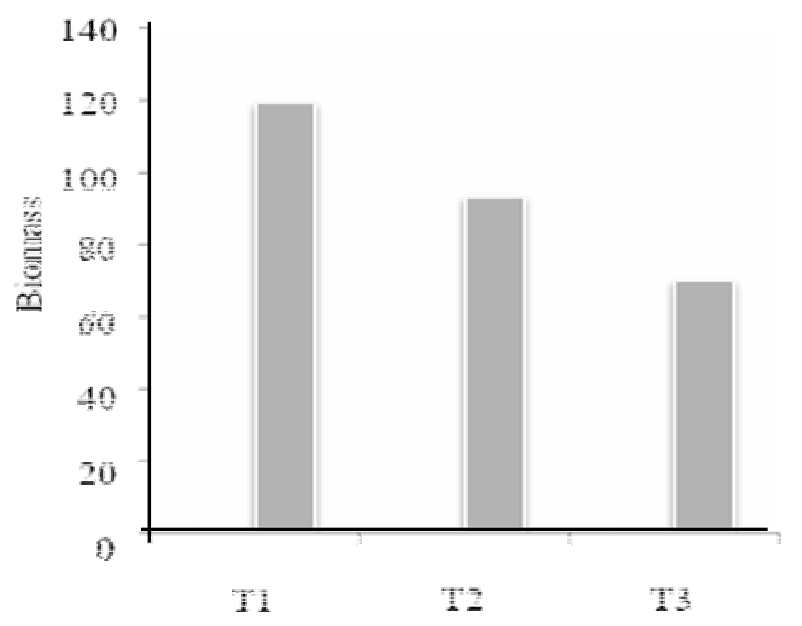

Fig. 9. Measurement of total biomass (g) in different treatments

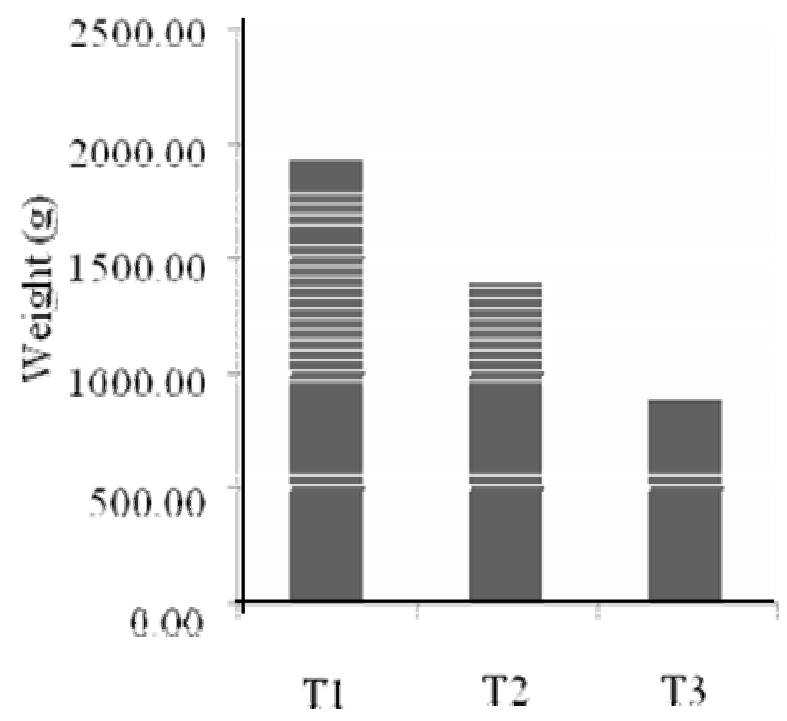

Fig. 8. Total production of tomato in different treatments

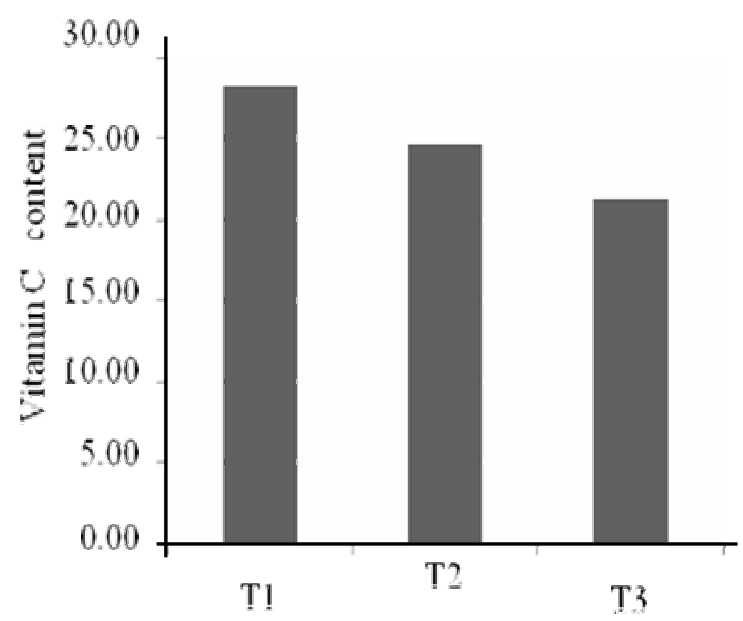

Fig. 10. Vitamin C content of tomato $(\mathrm{mg} / 100 \mathrm{~g})$ in different treatments

\section{Conclusion}

The NPK were high in Pangasius pond sediment. The total nitrogen content of the sediment was $0.30 \%$ which was almost similar to the compost manure (0.4-0.5\%). The organic carbon content was also very high in PPS sediment. By considering all the characters, it is concluded that treatment $\mathrm{T}_{1} i$. e., plants grown at $100 \%$ Pangasius pond sediment showed the best performance followed by $T_{2}$ and $T_{3}$. Besides, PPS performed the high potential on vegetables (tomato) production in bag gardening. It was interesting that negligible PPS had the potential to grow vegetables with better production without any manure and chemical fertilizers. Therefore, PPS can reduce the use of chemical fertilizers especially urea and this practice could be environment friendly and cost-effective. 


\section{References}

BARI, 1998. Summer Tomato (Booklet in Bengali). Horticulture Research Centre, Bangladesh Agricultural Research Institute, Joydebpur, Gazipur.12pp.

Bhuiyan, N.I. 1988. Co-ordinate project on potassium studies progress report. BARI, Joydevpur, Gazipur, p. 1-45.

Black, C.A. 1965. Methods of soil analysis.Part 1 \& 2. Amer. Soc. Agron. Inc. Publisher, Medison, Wisconsin, USA. p. 371-375.

Bouyoucos, G.J. 1927. The hydrometer as a method for the mechanical analysis of soils. Soil Sci., 23: 343-353.

DoF. 2005. Fisheries Statistical Yearbook of Bangladesh (2003-2004), Fisheries Resources Survey System, Fish Fortnight Compendium, Department of Fisheries, Ministry of Fisheries \& Livestock, Government of the Peoples Republic of Bangladesh. p. 45-67.

DoF. 2009. Fishery Statistical Yearbook Bangladesh.Fisheries Resources Survey System, Department of Fisheries, Ministry of Fisheries and Livestock, Dhaka, Bangladesh. p. 123-134.

DoF. 2010. Fisheries Statistical Yearbook of Bangladesh (2008-2009), Fisheries Resources Survey System, Fish Fortnight Compendium, Department of Fisheries, Ministry of Fisheries \& Livestock, Government of the Peoples Republic of Bangladesh. p. 102-103.

DoF. 2011. Fisheries Statistical Yearbook of Bangladesh (2009-2010), Fisheries Resources Survey System, Fish Fortnight Compendium, Department of Fisheries, Ministry of Fisheries \& Livestock, Government of the Peoples Republic of Bangladesh. p. 123-124.

Edwards, P. and Hossain, M.S. 2010. Bangladesh seeks export markets for striped catfish. Global Aquaculture Advocate. p. 65-68.

Gomez, K.A. and A.A. Gomez. 1984. Statistical procedures for agricultural research. Int. Rice Res. Inst., John Wiley \& Sons, New York. p. 139-240.

Haque, M.M. 2009. Emerging Pangasius Aquaculture Dialogue (PAD) Standards: Can Bangladesh Comply with? Paper presented in the workshop on Pangasius Aquaculture Dialogue (PAD) at ARD Lab, Central Library, Bangladesh Agricultural University, Mymensingh 22 August 2009. 45pp.

Hepher, B. 1965.The effect of impoundment on chemical and textural changes in fish ponds bottom soil. Bamidgeh, 17(3): 71-80.

Jackson, M.L. 1986. Soil chemical analysis. Prentice-Hall International, Inc., Englewood Cliffs, N.J., USA. 498pp.

Kalloo, D. 1985. Tomato.Allied publishers Pvt. Ltd. India. 33pp.

Karim , M.R. 2009. Properties of some selected soil series of floodplain and hill soils of Bangladesh. MS Thesis, Department of Soil Science, Bangladesh Agricultural University, Mymensingh. 43pp.

Matt, K.J. 1970. Colorimetric determination of phosphorus in soil and plant materials with ascorbic acid. Soil Sci., 109: 214-220.

Monir, M.S. 2009. A study on technical aspects of Pangasius (Pangasianodon hypophthalmus) farming in Mymensingh region. MS Thesis, Department of Fisheries Management, Bangladesh Agricultural University, Mymensingh. 58pp.

Munir, S.A.M. 2009. Socio-economic impacts and sustainability of Pangasius (Pangasianodonhypophthalmus) farming in Trishalupazila under Mymensingh, Bangladesh. MS Thesis, Institute of Aquaculture, University of Stirling, Stirling, Scotland, UK. 56pp.

Page, L.R. 1982.Methods of soil analysis.Part 1. American Soc. of Agron. Pub., USA. 156pp.

Pandey, R.K., Saxena, M.C. and Sing, V.B. 1978. Growth analysis of blackgram genotypes. Indian J. Agric. Sci.,48: $466-473$.

Sarker, M.T. 2000. Panguschash Babastapana (Management of Pangusculture). A fisheries leafleat.Sheuli, ComillaCantt., Comilla, Bangladesh (in Bengali) p. 39-44.

Weir, W.W. 1989.Soil science, its principle and practice. J.B. Lippincott Co. Philadelphia, USA. 55pp. 